\section{Von der Pathophysiologie zu neuen Entwicklungen in der Pharmakotherapie des Asthma bronchiale - ein Blick in die Zukunft}

\section{Einleitung}

Die Therapie des Asthma bronchiale lehnt sich zunehmend an die pathophysiologischen Grundlagen dieser Erkrankung an und basiert auf drei wichtigen Ansätzen: der Meidung auslösender Faktoren, der antiinflammatorischen und der antiobstruktiven Pharmakotherapie. Therapeutisches Ziel ist: a) die Erhaltung/Verbesserung der Lebensqualität, b) die Steigerung der Lungenfunktion mit Unterbindung von u.U. lebensbedrohlichen Asthmaanfällen, c) damit die Vermeidung von irreversiblen Umbauvorgängen (remodelling), bei d) gleichzeitiger Minimierung von Nebenwirkungen in der Langzeittherapie.

Neuere in Deutschland zugelassene Substanzen und Applikationsformen betreffen den Leukotrienrezeptorantagonisten Montelukast, das Kombinationspräparat Salmeterol/Fluticasondipropionat und ein mittels HFA (Hydroflouralkan) betriebenes BDP (Beclomethasondipropionat)-haltiges Dosieraerosol, das durch einen hohen Anteil respirabler Partikel (Partikelgröße $<3 \mu \mathrm{m}=>30 \%$ ) eine hohe pulmonale Deposition (>50\%) gewährleistet [1-5]. Weitere inhalative Kombinationspräparate (z.B. Formoterol/Budesonid) und andere Glukokortikosteroide (Mometason-Furoat, Triamcinolonacetonid, Ciclesonid) werden wahrscheinlich in naher Zukunft folgen $[6,7]$. Die jüngste Entwicklung therapeutischer Substanzen zur Behandlung des Asthma bronchiale imponiert daher durch die Etablierung neuer Kombinationspräparate oder durch die Modifizierung pharmakokinetischer/-dynamischer Eigenschaften schon etablierter Substanzen.

Die vorliegende Übersicht soll anhand der aktuellen Literatur und der jüngst auf internationalen Kongressen vorgestellten Arbeiten einen Überblick über die Entwicklung in der Pharmakotherapie des Asthma bronchiale geben.

\section{Weiterentwicklung bekannter Substanzen}

\section{Physiologie des neuronalen Systems}

Die neuronale Kontrolle des Asthma bronchiale erfolgt mediatorvermittelt über das sympathische (adrenerge und nichtadrenerge) und das parasympathische (cholinerge und nichtcholinerge) Nervensystem der Lunge. Beide Systeme befinden

Pneumologie 2000; 54: 345-354

(c) Georg Thieme Verlag Stuttgart · New York ISSN 0934-8387

\author{
A. Gillissen, H. Schäfer, S. Tasci, S. Ewig
}

Medizinische Klinik und Poliklinik II, Bonn sich beim Lungengesunden im Gleichgewicht. Das sympathische System wird über die Aktivierung folgender Rezeptoren gesteuert: $\alpha_{1^{-}}, \alpha_{2^{-}}, \beta_{1^{-}}, \beta_{2^{-}}$und $\beta_{3}$-Rezeptor. Die tiefen Atemwege sind reich an $\beta$-Rezeptoren, wobei sich die Rezeptorendichte von $\beta_{2}$ - zu $\beta_{3}$-Rezeptoren im Verhältnis von $3: 1$ verhält. Die medikamentöse Stimulation von $\beta_{2}$-Rezeptoren führt nicht nur zur Bronchodilatation, sondern reduziert die Mastzellendegranulation und verringert die Aktivität des cholinergen Nervensystems $[8,9]$. Über die $\beta_{3}$-Rezeptoren ist dagegen noch relativ wenig bekannt.

Das parasympathische Nervensystem beinhaltet afferente und efferente Nerven, die, wie histologische Studien zeigen, häufig im Bereich der zentralen Atemwege nachzuweisen sind und in der Peripherie an Dichte abnehmen. Die postganglionären parasympathischen Nerven innervieren direkt die glatte Bronchialmuskulatur und mukusproduzierende Zellen, nicht aber das Bronchialepithel oder das Bronchialgefäßsystem [10]. Dabei werden die postsynaptischen Neurone durch präsynaptisch sezerniertes Acetylcholin (ACh) aktiviert. Untersuchungen mittels Radioligandenbindung und Autoradiographie zeigen, dass ACh über die Aktivierung von Muscarinrezeptoren wirkt, von denen insgesamt vier Subtypen bekannt sind $\left(\mathrm{M}_{1-4}\right)$ [11]. Für die obstruktiven Atemwegserkrankungen ist von den insgesamt 4 Muskarinrezeptorsubtypen $\left(\mathrm{M}_{1-4}\right)$ insbesondere der $\mathrm{M}_{3}$-Rezeptor von pathophysiologischer Bedeutung, da seine Aktivierung zur Muskelkontraktion (Atemwegsobstruktion) und zur gesteigerten Mukussekretion (auch durch $\mathrm{M}_{1}$-Rezeptoraktivierung) führt. Die medikamentöse Blockade von Muskarinrezeptoren $\left(\mathrm{M}_{1}\right.$ und $\left.\mathrm{M}_{3}\right)$, z.B. mittels Ipratropiumbromid, bedingt über eine Verminderung der ACh-Freisetzung $\left(\mathrm{M}_{1}\right.$-Blockade) und der dadurch zusätzlichen ACh-Unempfindlichkeit der Bronchialmuskulatur $\left(\mathrm{M}_{3}\right.$-Blockade) eine Bronchodilatation [10,12,13]. Da aber der nicht-selektive Muskarinrezeptorblocker Ipratropiumbromid auch $\mathrm{M}_{2}$-Rezeptoren antagonisiert, kommt es $\mathrm{zu}$ einer unerwünschten Gegenregulation. Aus pathophysiologischer Sicht erscheint daher für die Behandlung obstruktiver Atemwegserkrankungen eine Substanz mit selektiver Inhibition der $\mathrm{M}_{3}$-Rezeptoren erfolgversprechender.

Eine weitere neuronal interessante Rezeptorfamilie sind die

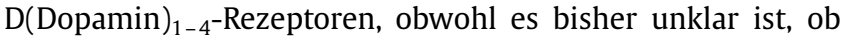
die sensorischen Nervenfasern und deren Nervenenden in der humanen Lunge dopaminerge Rezeptoren besitzen. So konnten Bonner et al. (1998) nachweisen, dass die selektive $\mathrm{D}_{2^{-}}$ Rezeptoraktivierung einen positiven Effekt auf Bronchokonstriktion, Luftnot, Mukusproduktion und Hustenreiz hat [14]. 


\section{$\beta_{2}$ - und $D_{2}$-Rezeptoraktivierung}

Die Substanz AR-C68397AA ist ein Wirkstoff mit einem dualen Wirkprinzip, der simultan sowohl den $\beta_{2^{-}}$als auch den $\mathrm{D}_{2}$-Rezeptor spezifisch stimulieren kann. In-vitro-Untersuchungen demonstrierten an Meerschweinchen-Tracheen die hohe $\beta_{2}$-Aktivität. Die prozentuale Relaxation in nanomolaren Konzentrationen lag dabei um ca. 20\% niedriger als die von Isoprenalin. Die $\mathrm{D}_{2}$-Rezeptoraktivität (gemessen an der Ohrarterie des Kaninchens) erreichte ebenfalls im nanomolaren Bereich ihr Wirkungsmaximum [15]. Untersuchungen in vivo demonstrierten bei Hunden, denen AR-C68397AA ( $5 \mu \mathrm{g} /$ $\mathrm{kg}$ ) mittels Aerosol verabreicht wurde a) ca. eine Halbierung des Capsaicin-induzierten Hustenreflexes, b) eine Reduktion (bis zu 66\%) der ammoniakinduzierten Mukusproduktion, und c) eine Rezeptorbindungszeit von $>4 \mathrm{~h}$. An Nebenwirkungen trat ab einer Substanzkonzentration von $30 \mu \mathrm{g} / \mathrm{kg}$ Erbrechen auf [16]. Aufgrund des Wirkprinzips eignet sich diese Substanz eher für die Therapie der COPD und weniger zur Behandlung des Asthma bronchiale. Ziele der derzeit durchgeführten Phase-IIb/IIla-Studien sind die Evaluation der klinischen Effektivität und das zukünftige Einsatzgebiet (COPDAsthma) von AR-C68397AA.

\section{Muskarinrezeptorblocker}

Tiotropiumbromid (Ba 679 BR) ist eine Weiterentwicklung des Ipratropiumbromid, dessen parasympatholytische Wirkung stärker ist und länger andauert als die der Vorläufersubstanz [17]. Da es sich aber bei dieser Neuentwicklung um eine Substanz handelt, die primär bei der COPD Anwendung finden wird, soll hier auf eine weitere Beschreibung verzichtet werden.

\section{Physiologie der Phosphodiesterasen}

In den vergangenen Jahren wurden insgesamt 8 verschiedene Isoenzym-Familien der Phosphodiesterasen (PDE; $3^{\prime}: 5^{\prime}$-zyklisches Nucleotid 5'-Nucleotidhydrolase; EC 3.1.4.17) identifiziert; insgesamt sind 20-30 Isoenzymsubtypen beschrieben. PDEs sind Enzyme, die in unterschiedlicher Weise die 3'Ribose-Phosphatbindung von zyklischen 5-Nucleotid-Monophosphaten (cAMP, cGMP) hydrolysieren. Beide Monophosphate vermitteln intrazellulär über eine rezeptorvermittelte Reaktion die Wirkung verschiedener Neurotransmitter, Hormone und Autakoide. In der Zelle werden die cAMP-abhängige Proteinkinase A (PKA) und die cGMP-abhängige Proteinase $G$ (PKG) aktiviert, die beide eine Bronchiodilatation induzieren [18-20]. Die verschiedenen PDE-Isoenzymsubtypen werden zelltypen- und speziesspezifisch sehr unterschiedlich exprimiert. In humanen Trachealmuskelzellen wurden z.B. PDE2, 3, 4 und 5 nachgewiesen. In Mastzellen, neutrophilen und eosinophilen Granulozyten findet sich überwiegend PDE4. Auch Lymphozyten besitzen verschiedene Subtypen. Die Hemmung von PDEs führt nicht nur zu einer Muskelrelaxation, sondern auch zur Reduktion des Zellaktivitätsgrades von Entzündungszellen (z. B. Oxidantienfreisetzung), weswegen PDE-Inhibitoren - ebenso wie dem Theophyllin - ein antientzündlicher Wirkungsansatz zugesprochen werden $[21,22]$.

\section{Phosphodiesteraseinhibitoren}

Phosphodiesteraseinhibitoren der ersten Generation waren durch ihre zahlreichen Nebenwirkungen (Arrhythmien, Tachykardien, Vasodilatation bei PDE3-Inhibition; Übelkeit und Erbrechen bei PDE4-Inhibition) für die Praxis unbrauchbar $[21,23]$. Eine Weiterentwicklung bilden die aktuell evaluierten selektiven PDE4-Hemmer, die sich nicht nur durch ein antiobstruktives, sondern auch ein signifikantes antiinflammatorisches Wirkungsspektrum auszeichnen [24,25]. Verschiedene PDE4-Hemmer, die hier exemplarisch vorgestellt werden, befinden sich derzeit im Entwicklungsstadium.

Harbinson et al. (1997) evaluierten bei Patienten $(n=54)$ mit einem Asthma bronchiale den oral applizierbaren PDE4Inhibitor CDP 840. Diese Studie hatte ein dreiarmiges, doppelt verblindetes, placebokontrolliertes Studiendesign: a) $15 \mathrm{mg} /$ 2×/d über 9,5 Tage; Zielparameter: Protektion vor einer Allergenprovokation ( $\mathrm{p} 1-$ Antigen der Hausstaubmilbe Dermatophagoides pteronyssinus), b) $15 \mathrm{mg} / 2 \times / \mathrm{d}$ über 9,5 Tage; Zielparameter: protektiver Effekt nach Histaminprovokation, und c) 15 und $30 \mathrm{mg}$ als Einmaldosis; Zielparameter: bronchodilatativer Effekt [26]. Verbesserungen der $\mathrm{FEV}_{1}$, der asthmatischen Frühreaktion und der Atemwegsobstruktion nach Histaminprovokation (als Maß für die bronchiale Hyperreaktivität) konnten nicht erzielt werden. Lediglich die allergische Spätreaktion wurde mit einer 30\%igen Reduktion signifikant $(p=0,016)$ beeinflusst. Die bei dieser Substanzgruppe häufig beobachtete Übelkeit mit Erbrechen trat im Vergleich zur Plazebogruppe unter CDP 840 nicht vermehrt auf [26].

Ein weiterer neuer PDE4-Hemmer der zweiten Generation ist SB 207499 Ariflo $^{\circledR}$ (c-4-cyano-4-[3-cyclopentyloxy-4-methoxyphenyl-r-1-cyclohexane carboxylic acid]) [24]. Es liegen von SB 207499 mittlerweile Daten sowohl bei Patienten mit einem Asthma bronchiale als auch mit einer COPD vor [2730]. Compton et al. (1999) behandelten 309 Asthmatiker $\left(\mathrm{FEV}_{1} 50-80 \%\right)$ mit $5 \mathrm{mg}, 10 \mathrm{mg}$ oder $15 \mathrm{mg}$ SB207499 (2×/d, orale Applikation, Behandlungsdauer: 6 Wochen) [27]. Die erzielte Lungenfunktionsverbesserung $\left(\mathrm{FEV}_{1}\right.$ und Atemstoßtest $\mathrm{PEF}=$ peak expiratory flow) verhielt sich entsprechend der verabreichten Dosis und war bei höchster Dosierung am besten. Die mittlere $\mathrm{FEV}_{1}$-Verbesserung (gegenüber dem Ausgangswert) betrug am Studienende $280 \mathrm{ml}$ (Verumgruppe) gegenüber $110 \mathrm{ml}$ (Plazebogruppe; $\mathrm{p}=0,056$ ). Die Verumgruppe litt etwas häufiger an Kopfschmerzen, Erbrechen und Dyspepsie [27]. Die auf der Jahrestagung der European Respiratory Society 1999 von der gleichen Arbeitsgruppe vorgestellten Ergebnisse der mit SB207499 behandelten 303 Asthmatiker $\left(\mathrm{FEV}_{1}: 50-80 \%_{\text {soll }}\right.$, alle erhielten begleitend inhalative Kortikosteroide; SB207499-Dosis: 5, 10, $15 \mathrm{mg}$, orale Gabe $2 \times / d$ über 6 Wochen) erbrachten folgende Lungenfunktionsverbesserungen $\left(\mathrm{FEV}_{1}, 2 \times 15 \mathrm{mg} / \mathrm{d}\right.$, Vergleich gegenüber Plazebo): $160 \mathrm{ml} 4 \mathrm{~h}$ nach Einnahme $(\mathrm{p}=0,031) ; 210 \mathrm{ml}$ nach 2 Wochen $(p=0,006) ; 160 \mathrm{ml}$ bei Studienende $(p=0,062)$ [28].

Eine Interaktion mit in der Inneren Medizin häufig verabreichten Medikamenten wie Prednisolon, Theophyllin, Salbutamol, Digoxin, aber auch Warfarin ließ sich ausschließen [30]. D4418 (8-methoxyquinoline-5-[N-(2,5-dichloropyridin3-yl]carboxamide) ist ein weiterer oral applizierbarer PDE4- 
Hemmer mit einer $\mathrm{IC}_{50}$ bei $2 \cdot 10^{-7} \mathrm{~mol} / \mathrm{l}$. Im Tiermodell (Ratte, Frettchen, Meerschweinchen) steigerte D4418 intrazelluläre cAMP-Konzentrationen, reduzierte die LPS (Lipopolysaccaride)-induzierte Tumornekrosefaktor-(TNF) und Interleukin5(IL-5)-Steigerung, und senkte damit die allergische Frühreaktion mit Reduktion der Atemwegsobstruktion um 40\% und die der Spätreaktion um 100\% [31]. In der inzwischen durchgeführten Phase-I-Studie konnte nach einer oralen Gabe (200 mg) eine Toxizität (Plasmaspiegel von Cmax 1,5 $\mu \mathrm{g} / \mathrm{ml}$ ) ausgeschlossen werden [31].

Zusammengefasst zeigten PDE4-Inhibitoren der zweiten Generation in den am Menschen durchgeführten Studien nur schwache bronchodilatative Effekte.

\section{Hemmung der Arachidonsäureprodukte}

Produkte des Arachidonsäurezyklusses (Leukotriene, Thromboxane, Prostaglandine) sind typische Mediatoren im asthmatischen Entzündungsgeschehen. Leukotrien-D4 (LTD4) erhöht z.B. die vaskuläre Permeabilität, steigert die bronchiale Mukusproduktion und fördert die bronchiale Muskelkontraktion. In der Vergangenheit wurde daher erfolgreich versucht a) die Synthese zu inhibieren oder b) die entsprechenden Rezeptoren am Ende dieser Entzündungskaskade zu blockieren. Jüngstes Beispiel ist die Markteinführung (in Deutschland 4/1998) von Montelukast, einem LTD4-Rezeptorblocker. Pranlukast, Zafirlukast (beides Leukotrienrezeptorblocker) und Zileuton (ein Leukotriensyntheseinhibitor) sind weitere in einigen Ländern verfügbare antiinflammatorisch wirksame Substanzen dieser Gruppe, deren Markteinführung in Deutschland nach gegenwärtigem Kenntnisstand nicht vorgesehen ist. Auch ist eine Neu- und Weiterentwicklung der Leukotrien-modulierenden Substanzen in naher Zukunft nicht zu erwarten. Thromboxane - insbesondere das Thromboxan- $\mathrm{A}_{2}$ - haben starke bronchokonstriktorische Fähigkeiten. Insbesondere japanische $\mathrm{Ar}$ beitsgruppen befassen sich mit der Hemmung von Produkten des Cyclooxygenase-Weges und hier insbesondere der Thromboxane, von denen Seratrodast ein älterer, schon seit den 80er Jahren evaluierter Inhibitor ist [32 - 34].

Arakida et al. (1998) untersuchten in vitro (isolierte Meerschweinchen-Tracheen) das pharmakologische Profil eines neuen Thromboxan- $\mathrm{A}_{2}$ ( TXA $_{2}$ )-Rezeptorantagonisten mit dem Kürzel YM158 [35]. Die Untersuchungen erfolgten im Vergleich zu Montelukast und Seratrodast, einem $\mathrm{TXA}_{2}$-Antagonisten der ersten Generation. YM158 besitzt sowohl eine LTD4- als auch eine TXA ${ }_{2}$-antagonistische Wirkung. Die LTD4Blockade war allerdings 6,5-mal schwächer als die von Montelukast und 2,5-mal stärker als die von Seratrodast. YM158 hemmte auch die prostaglandinverursachte $\left(\mathrm{PGD}_{2}\right.$ und $\mathrm{PGF}_{2 \alpha}$ ) Bronchuskontraktion, nicht aber die von Histamin oder Carbachol [35]. Ein weiterer $\mathrm{TXA}_{2}$-Rezeptorblocker ist AA-2414 [36]. Hoshino et al. (1999) evaluierten AA-2414 bei Asthmatikern ( $80 \mathrm{mg} / \mathrm{d}$, orale Gabe, Studiendauer: 4 Monate) und fanden eine ganze Reihe von positiven klinischen Effekten (Signifikanzen gegenüber Plazebo): Symptomen-Score $(\mathrm{p}<0,05)$, PEF $(\mathrm{p}<0,01)$, PEF-Variabilität $(\mathrm{p}<0,01)$ und bronchiale Hyperreaktivität $(\mathrm{p}<0,01)$ [33]. Untermauert wurde dieses Ergebnis durch die signifikante Verbesserung diverser Entzündungsmarker: Senkung der submukösen Eosinophilenzahl in bronchialen Biopsien $(\mathrm{p}<0,05)$, der Anzahl RANTES (regulated and normal T-lymphocyte expressed and secreted human cytokine $)-(p<0,05)$, Makrophagen-inflammatorisches Protein (MIP)-1 alpha $(\mathrm{p}<0,05)$ und Eotaxin- $(\mathrm{p}<0,01)$ exprimierender Zellen des Bronchialepithels und der submukösen Zellen [37]. In einer weiteren nur an einer kleinen Probandenzahl ( $n=6$, cross-over Design) durchgeführten Studie wurden bei milden bis moderat erkrankten allergischen Asthmatikern die klinische Wirkung von Pranlukast (450 mg/ d, oral), Seratrodast $(80 \mathrm{mg} / \mathrm{d}$ oral) und Ozagrel $(800 \mathrm{mg} / \mathrm{d})$, einem $\mathrm{TXA}_{2}$-Synthetaseinhibitor, miteinander verglichen [38]. Zielkriterium war die Senkung der allergischen Früh- und Spätreaktion. Während Pranlukast die Frühreaktion um 80,5\% ( $\mathrm{p}<0,0001)$ und die Spätreaktion um 54,6\% senkte, ergaben sich bei Ozagrel eine 39,5\%ige $(p=0,043)$ Senkung für die Früh- und keine Signifikanz für die Spätreaktion, während Seratrodast keinen entsprechenden Suppressionseffekt aufwies [38]. Der Thromboxanrezeptor-Antagonist BAY u 3405 (20 mg orale Applikation) vermochte bei 12 milden Asthmatikern im Mittel zwar den $\mathrm{FEV}_{1}$-Abfall nach inhalativer Prostaglandin-D2-Provokation $(p=0,0002)$ nicht jedoch die nach Fahrradergometerbelastung und kalter Luft ausgelöste Atemwegsobstruktion zu reduzieren [39].

Insgesamt scheinen die $\mathrm{TXA}_{2}$-Inhibitoren offenbar nur einen geringen klinischen Effekt beim Asthma bronchiale zu besitzen. Die überaus positiven Ergebnisse der Untersuchungen von Hoshino et al. (1999) sind daher auch vor dem Hintergrund des gewählten Studienaufbaus und Methodik kritisch zu würdigen und bedürfen einer Bestätigung.

\section{Glukokortikosteroide}

Eine Steigerung der pharmakologischen Wirksamkeit von Glukokortikosteroiden erscheint schwierig und ist klinisch eher von sekundärer Bedeutung, zumal potente Glukokortikosteroide zur Verfügung stehen. Möglicherweise könnte sich trotzdem in der Entwicklung inhalativer Glukokortikosteroide zumindest langfristig eine interessante Perspektive ergeben, da eine weitere Reduzierung der Nebenwirkung überaus wünschenswert wäre. Das optimale topisch wirksame Glukokortikosteroid wäre eine stark antiinflammatorisch wirksame Substanz, die in der Lunge biologisch aktiv und von der Molekülstruktur stabil wäre, die aber im Blutkreislauf innerhalb kürzester Zeit abgebaut oder inaktiviert würde und somit systemisch keinen Effekt entfalten könnte. Mit der Entwicklung sog. „Soft-Steroids“ wird ein solcher Weg begangen. So könnte als möglicher Ansatzpunkt die Entwicklung hydrolisierbarer Glukokortikosteroidmoleküle mit einer systemischen Halbwertszeit von wenigen Minuten, oder „dissoziierte“ Glukokortikosteroide, die zur Reduktion unerwünschter Nebenwirkungen nur aus einem verkleinerten, dissoziierten Molekül bestehen, aus chemisch-pharmakologischer Sicht ein gangbarer Weg für die nächsten Jahre oder des nächsten Jahrzehnts sein. Veröffentlichungen über diesen seitens der Hersteller potenziell attraktiven und hoch-kompetitiven Aspekt, sind verständlicher Weise ausgesprochen rar. Kürzlich jedoch erlaubte uns die Fa. GlaxoWellcome einen kleinen Blick in die Pipeline ihrer neuen Pharmaka zur Therapie obstruktiver Atemwegserkrankungen. Demnach befinden sich bei GlaxoWellcome derzeit zwei hydrolisierbare Glukokortikosteroide, GR215846 und GR250495, in der Entwicklung. GR215846 besitzt beispielsweise bei einer Plasmahalbwertszeit von weniger als einer Minute einen sehr hohen Wirkungsgrad am Glukokortikosteroidrezeptor. Als mittlere Kon- 
zentration, die zu einer 50\%igen Hemmung der spezifischen Bindung $\left(\mathrm{IC}_{50}\right)$ führt, sind lediglich $2 \mathrm{nmol} / \mathrm{l}$ nötig. GR250495 ist etwas weniger potent, denn die $\mathrm{IC}_{50}$ liegt bei $12 \mathrm{nmol} / \mathrm{l}$ und die Plasmahalbwertszeit bei fünf Minuten. Beide Verbindungen sind in vivo stabil. Vorstudien mit GR215846 haben bei einer allerdings nur einmal durchgeführten Applikation systemische Effekte beim Menschen ausschließen können, so dass mit diesem Steroid jetzt eine „proof-of-concept“-Studie initiiert wurde [40].

\section{Entwicklung neuer antiinflammatorisch wirksamer Substanzen}

Der Schwerpunkt in der Entwicklung neuer Substanzen und Substanzgruppen liegt in der antiinflammatorischen Therapie. Mit zunehmender Kenntnis der immunpathologischen Vorgänge beim Asthma bronchiale wird versucht, einzelne Komponenten und nicht, wie bei der Glukokortikosteroidtherapie, die ganze Bandbreite dieses sehr komplexen Entzündungsgeschehen zu inhibieren. Aktuelles Beispiel dieser Entwicklung ist die selektive Hemmung der Leukotriensynthese bzw. die der Leukotrienrezeptoren (s.o.).

Im Folgenden sollen nun einige dieser sich in der Entwicklung befindlichen Therapieansätze vorgestellt werden.

\section{Immunglobuline}

Immunglobuline (Ig) sind Glykoproteine, die von Plasmazellen („umgewandelte“ B-Lymphozyten) produziert werden und als Antikörper fungieren. Insgesamt gibt es fünf isotypische Ig-Varianten mit entsprechenden Untergruppierungen. Für die allergische Reaktion ist das Immunglobulin E (IgE) wegen der dadurch vermittelten Bindung eines Allergens mit zellulären Oberflächenrezeptoren von Mastzellen und basophilen Granulozyten das wichtigste Immunglobulin. Die Entzündungszellen werden dadurch aktiviert und setzen für die allergische Reaktion charakteristische Mediatoren (z.B. Histamin, Leukotriene, Zytokine, Prostaglandine, andere chemotaktische Faktoren) frei. Neben dem Asthma bronchiale gibt es noch andere Erkrankungen, die IgE-assoziiert sind, z.B. Wurminfektionen, die allergische Rhinitis, bestimmte Formen der Urticaria und das Angioödem.

Die Identifikation von IgE durch Johansson und Bennick (1967), und Ishizaka (1967), und die Entdeckung, dass sich IgE mit einer hohen Affinität an den FceR1-Rezeptor auf Mastzellen und basophilen Zellen bindet, hat die Möglichkeit eröffnet, über die FcrR1-Blockade allergische Reaktionen spezifisch zu inhibieren, da über diese Rezeptorbindung die allergische Sofortreaktion ausgelöst wird [41-43]. Mittlerweile wurde ein weiterer Rezeptor (FcعR2) auf mononukleären, dendritischen, Epithelzellen und eosinophilen Granulozyten identifiziert, der u.a. die vermehrte Allergenaufnahme und Allergenpräsentation moduliert [44]. Der Antikörper muss also in der Lage sein, die FceR1-Bindungsregion auf dem IgEMolekül zu blockieren und somit die IgE-Zellinteraktion zu unterbinden (Abb.1). Dieser Ansatz wurde erstmalig von Bozelka et al. (1982) beschritten. Die in dieser frühen Experimentierphase verwendeten monoklonalen Antikörper führten allerdings noch zu unerwünschten Kreuzreaktionen [45]. Interessanter Weise wurde mit der Idee der IgE-Blockade ein altes Prinzip der Natur kopiert, denn anti-IgE-Antikörper

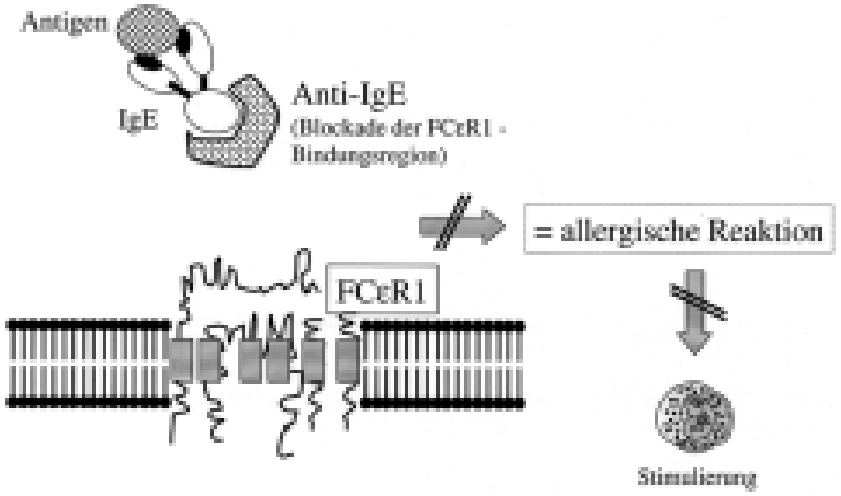

Abb. 1 Die spezifische Blockade der FceR1-Bindungsstelle innerhalb des lgE-Moleküls mittels eines monoklonalen Antikörpers verhindert die IgE-vermittelte allergische Reaktion, da die Verbindung zwischen $\mathrm{IgE}$ und dem zellulären Fc\&R1-Rezeptor dadurch unterbunden wird und somit eine Zellaktivierung ausbleibt (modifiziert nach [46]).

kommen bei vielen Erkrankungen vor, so z. B. der atopischen Dermatitis, der idiopathischen Urticaria, der rheumatoiden Arthritis/Vaskulitis, Lupus Erythematodes, Dermatomyositis, Pemphigus vulgaris und dem bullösen Pemphigoid [46]. Dabei reagieren (Auto-)Antikörper gegen die Fcع-Kette des IgE, gegen Epitope der $\alpha$-Ketten des FceR1-Rezeptors, oder es fördern IgG-Antikörper die Bindung von IgG-IgE-Komplexen an die zellulären FceR1-Rezeptoren.

Die Entwicklung eines tatsächlich für den praktischen therapeutischen Einsatz geeigneten hochspezifischen IgE-Antikörpers, der sowohl die allergische Früh- als auch die Spätreaktion hemmen kann, wurde durch die Notwendigkeit einer vollständigen Blockade der FceR1-Bindungsregion des IgEMoleküls ohne gleichzeitige Reaktion mit dem entsprechenden zellulären Rezeptor mit nachfolgender Zellaktivierung lange Zeit verzögert.

\section{Anti-IgE-Antikörper}

Derzeit werden Phase-III-Studien mit einem rekombinant hergestellten, monoklonalen, humanisierten (Modifizierung des murinen Antikörpers MAE11 durch Aminosäurenaustausch) Anti-IgE-Antikörper (rhuMAb-E25) durchgeführt. Für die Markteinführung von rhuMAb-E25 zur Therapie des Asthma bronchiale ist das Jahr 2001 projektiert.

In-vitro-Untersuchungen belegten, dass sich rhuMAb-E25 nicht an Basophilen und insbesondere nicht an den FceF1Rezeptor dieser Zellen bindet. Ferner führt rhuMAb-E25 nicht zu Kreuzreaktionen mit allergensensibilisierten Basophilen, hemmt jedoch die Histaminfreisetzung und die Kontraktion allergenstimmulierter humaner Lungenstreifen [47]. rhuMAbE25 wurde sowohl im tierexperimentellen und mittlerweile aber auch am Menschen in wissenschaftlichen Studien bei Allergikern (ohne Asthma) und Patienten mit einem allergischen Asthma bronchiale evaluiert [48-52]. Casale et al. (1997) behandelte in einer doppelt-verblindeten, plazebokontrollierten, Phase-II-Studie, 181 Graspollen-Allergiker mit rhuMAb-E25: i.v. Applikation ein Monat vor der „HeuschnupfenSaison“ (= Tag 0), gefolgt von $0,15 \mathrm{mg} / \mathrm{kg}$ s.c. oder i.v. oder $0,5 \mathrm{mg} / \mathrm{kg}$ i.v. an den Tagen 7 bis 84 (insgesamt 8 Applikatio- 
nen). In Abhängigkeit zu den individuellen Ausgangs-IgESerumkonzentrationen und der gewählten Dosis reduzierte rhuMAb-E25 die freien Serum-IgE-Spiegel [49]. Signifikante Unterschiede in der klinischen Wirksamkeit und der SerumIgE-Reduktion errechneten sich allerdings nicht. Bezüglich der Nebenwirkungen verhielten sich sowohl die Verum- als auch Plazebogruppe gleich [49]. 1997 erschienen die bisher wichtigsten Untersuchungen zur Therapie des allergischen Asthma bronchiale mit anti-IgE-Antikörpern [53]. In beiden, bei Patienten mit einem milden Asthma bronchiale durchgeführten Untersuchungen konnte mit rhuMAb-E25 (i.v. Applikation: $2 \mathrm{mg} / \mathrm{kg}$ an Tag 0; je $1 \mathrm{mg} / \mathrm{kg}$ an den Tagen 7, 14, $28,42,56$ und 70 [48]; bzw. $0,5 \mathrm{mg} / \mathrm{kg} 1 \times /$ Woche über 8 Wochen [50]) weder eine Verbesserung der Asthma-Symptome, der Lungenfunktion $\left(\mathrm{FEV}_{1}\right)$ noch eine Verringerung der bedarfsweise verwendeten inhalativen $\beta_{2}$-Agonisten erzielt werden $[48,50]$. Allerdings waren die untersuchten Patientenkollektive klein ( $\mathrm{n}=19$ bzw. 20) und der Asthmagrad mild $\left(\mathrm{FEV}_{1} \geq 70 \%_{\text {soll }}\right.$ ). Es fielen aber in beiden Studien einige Besonderheiten auf: So führte rhuMAb-E25 zu einem Anstieg der im Serum gemessenen Gesamt-IgE-, zu einem Abfall der freien IgE-Konzentrationen und einer 11-fachen Reduktion der Sputumeosinophilie. Die bronchiale Empfindlichkeit nach spezifischer inhalativer Allergenprovokation $\left(\triangle \mathrm{PC}_{15}\right.$ Allergen $)$ nahm signifikant ab (Tag 27: $\mathrm{p}=0,0009$; Tag 55: $\mathrm{p}=0,0005$; Tag 77: $p \leq 0,002$ ) [48]. Fahy et al. (1997) beschrieb eine rhuMAb-E25-vermittelte Reduktion des Allergen-induzierten $\mathrm{FEV}_{1}$-Abfalls von $30 \pm 10 \%$ auf $18,8 \pm 8 \%$ in der allergischen Frühreaktion, und eine $\mathrm{FEV}_{1}$-Reduktion von $24 \pm 20 \%$ auf $9 \pm 10 \%$ in der allergischen Spätreaktion [50]. Die $\Delta \mathrm{PC}_{20}$ für Methacholin stieg um das 1,6-fache an, wobei sich allerdings erst bei Studienende eine Signifikanz $(\mathrm{p}=0,05$ an Tag 76) errechnen ließ [48,50]. Die Stärken der rhuMAb-E25-Therapie liegen nach diesen beiden Untersuchungen in einer guten Reduktion der spezifisch-allergischen zellulären Immunreaktion und der allergen-provozierten Bronchokonstriktion, jedoch bestenfalls schwach in der Beeinflussung der unspezifischen bronchialen Hyperreaktivität, nicht jedoch in einer Lungenfunktionsverbesserung. Diese Interpretation wurde allerdings in einer viel größeren Untersuchung von Metzger et al. (1998) relativiert, in der an 317 Asthmatikern gegenüber Plazebo der Effekt einer unterschiedlichen rhuMAb-E25-Dosis (niedrig: 0,006; vs. hoch: $0,014 \mathrm{mg} / \mathrm{kg} / \mathrm{IU} / \mathrm{ml}$ ) untersucht wurde [52]. Dabei ließ sich die Steroiddosis der Verumgruppen signifikant $(\mathrm{p}<0,02)$, die des $\beta_{2}$-Mimetikaverbrauchs, des Symptomen-Scores, und die Asthma-Exazerbationsraten von $45 \%$ (Plazebo) auf $28 \% / 30 \%$ (niedrige/hohe Behandlungsdosis; $\mathrm{p}=0,03$ ) senken [52].

\section{Interleukine}

Das Zytokinnetzwerk ist sehr komplex und kann an dieser Stelle nur bezogen auf die Entwicklung der dort eingreifenden Pharmaka punktuell beschrieben werden. Ausgangspunkt einer allergischen Reaktion ist die Interaktion zwischen einem Allergen und einer antigenpräsentierenden Zelle (oder Zellen mit antigenpräsentierenden Eigenschaften), wozu mononukleäre Zellen (Makrophagen/Monozyten, Lymphozyten) und die dentritischen Zellen zusammengefasst werden. Diese Zellen verarbeiten das Allergen und präsentieren Lymphozyten die entsprechenden immunogenen Sequenzen auf ihrer Zelloberfläche, die ihrerseits eine Differenzierung in Th1- und Th2-Lymphozyten erfahren. Diese Zellen sind somit „initiie-

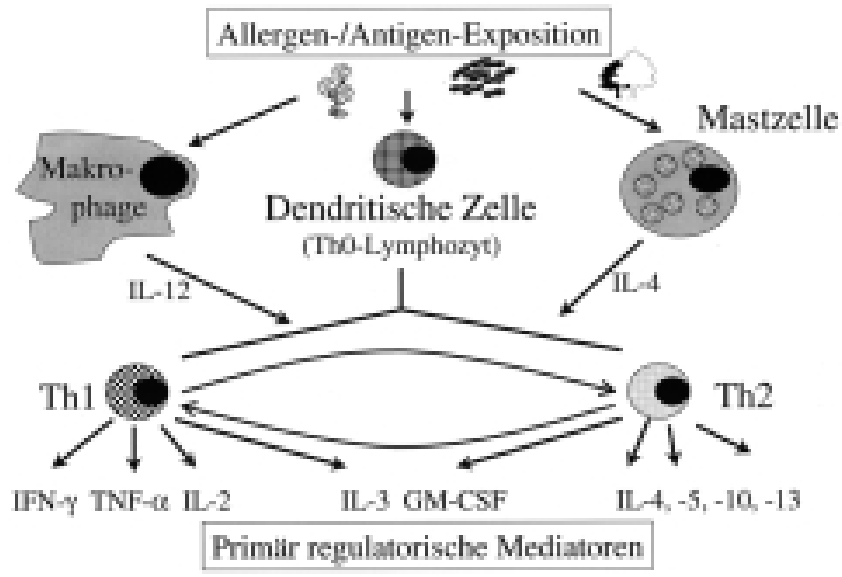

Abb. 2 Vereinfachte Darstellung der Th1- und Th2-Antwort nach Allergenexposition beim allergischen Asthma bronchiale (modifiziert nach [78]). IL- = Interleukin, IFN- $\gamma=$ Interferon-gamma, GM-CSF = granulocyte/macrophage stimulating factor, TNF- $\alpha=$ Tumornekrosefaktor-alpha, Th- = T-Lymphozyt.

rende und amplifizierende“ Zellen. Das für die Th1- und Th2Lymphozyten charakteristische Zytokinmuster (Abb. 2) steuert die nachfolgende immunologische Reaktion der sog. Effektorzellen (Mastzellen, basophile, neutrophile und eosinophile Granulozyten, Thrombozyten und Makrophagen), die wieder zu einer entsprechenden Reaktion auf der Effektorzielzellebene führt (Epithelzellen, Myofibroblasten, Muskelzellen). Die „Kommunikation“ dieser verschiedenen Zellen erfolgt dabei sowohl in synergistischer als auch antagonistischer Richtung mittels verschiedenster Mediatoren (Chemokine, Immunglobuline, Leukotriene, Prostanoide, biogene Amine) $[54,55]$. Die therapeutische Beeinflussung des Zytokinnetzwerkes zur Behandlung des Asthma bronchiale ist dabei ein möglicher Ansatz [56]. B-Lymphozyten werden z. B. zur IgE-Produktion im wesentlichen durch IL-4 aber auch durch IL-5, IL-6 und IL-13 angeregt, dem gegenüber stehen Interferon-gamma (IFN- $\gamma$ ), IL-8 und IL-12, die diese Reaktion antagonisieren. IL-3, IL-5 und GM-CSF (granulocyte/macrophage colony stimulation factor) sind bei allergischen, Eosinophilen-dominierten Erkrankungen, wie dem Asthma bronchiale, entzündungsfördernd. Während IL-5 selektiv die Eosinophilen-Produktion steigert, können dies IL-3 und GM-CSF auch für Neutrophile, Monozyten und Mastzellen. IL-5 ist unter diesen Mediatoren der stärkste Aktivator von eosinophilen Granulozyten, indem es die Lebensdauer dieser Zellen verlängert, die Apoptose verhindert, die zelluläre $\mathrm{LTC}_{4}$ (Leukotrien- $\mathrm{C}_{4}$ )-Synthese steigert und die Zellaktivität (zunehmende Degranulation) erhöht $[54,55]$. Bezüglich der Lebenszeitverlängerung von Eosinophilen ist das Zusammenspiel der o.g. Mediatoren von Bedeutung. Ein Mediator alleine ist nämlich schwächer wirksam als der gemeinsame Effekt von IL-3, IL-5 und GM-CSF [57]. Da eosinophile Granulozyten beim Asthma bronchiale regelmäßig in der BAL, in der Bronchialschleimhaut und im Lungengewebe nachgewiesen werden und die Zellmenge mit der Erkrankungsschwere korreliert, wird IL-5 als einer der wichtigsten Entzündungsmediatoren des Asthma bronchiale angesehen und prädisponiert zur therapeutischen Blockade, zumal auch über die Reduktion der Eosinophilenzahlen ein wirksamer antiinflammatorischer Effekt erzielt werden kann (Abb. 3) [58 -60]. 

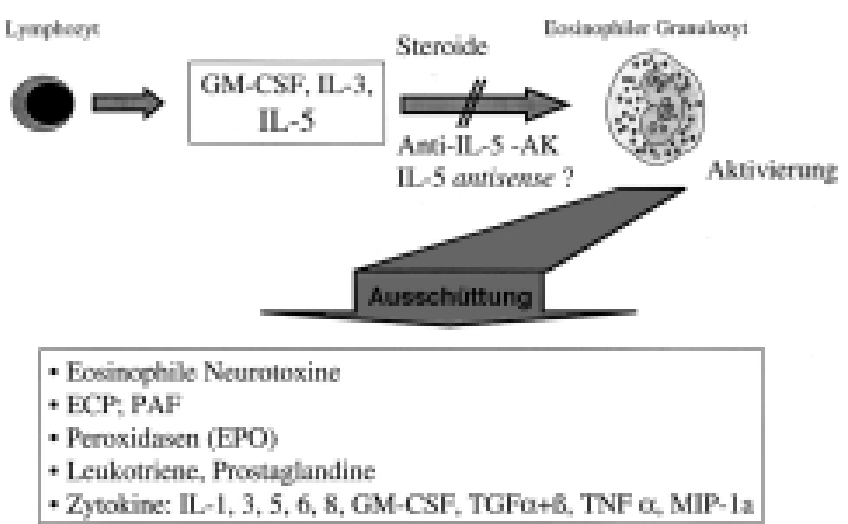

Abb. 3 Interleukin 5 (IL-5) fördert die Produktion eosinophiler Granulozyten, steigert deren Aktivität und die Lebenszeit. Die IL-5Hemmung - sei es durch einen selektiven Inhibitor, durch Kortikosteroide oder ein IL-5-antisense Oligonucleotid - führt zu einer Reduktion der Zellaktivität, der Zellzahl (Eosinophile) und der freigesetzten Entzündungsmediatoren.

\section{Anti-IL-5-Antikörper}

Bei Patienten mit einem symptomatischen Asthma bronchiale ließ sich in Abhängigkeit zu den in der BAL gemessenen IL-3-, IL-5- und GM-CSF-Konzentrationen eine erhöhte Überlebenszeit der aus Sputum oder peripherem Blut isolierten eosinophilen Granulozyten nachweisen. Die verlängerte Lebenszeit der Zellen kann in vitro unter Verwendung der entsprechenden Antikörper signifikant $(\mathrm{p}<0,05)$ reduziert werden [57,61]. Leckie et al. (1999) stellten die Ergebnisse der Therapie mit einem humanisierten Antikörper gegen IL-5 (SB240563) an Patienten mit einem allergischen Asthma $(n=24)$ auf dem Jahreskongress 1999 der American Thoracic Society vor [62]. Die Patienten erhielten entweder $2,5 \mathrm{mg} / \mathrm{kg}$ i.v. $(\mathrm{n}=8), 10 \mathrm{mg} / \mathrm{kg}$ i.v. $(\mathrm{n}=8)$ des SB-240563 oder Plazebo. Die Blut-Eosinophilenzahl sank bei der hohen Dosis bis zu einem Beobachtungszeitraum von 113 Tagen post-injectionem am stärksten (von initial $0,3 \pm 0,12 \times 10^{6}$ Zellen/l auf $<0,1 \times 10^{6}$ Zellen/l) und war von einem Abfall der Sputum-Eosinophilenzahl begleitet. Klinisch wurde die Wirkung kontrolliert mittels a) eines unspezifischen Provokationstests (Histamin; $\mathrm{PC}_{20}$ ) und b) mittels spezifischer Allergenprovokationstestung (allergische Sofort- und Spätreaktion). In der Histaminprovokation und in der allergischen Sofortreaktion ließ sich unter der anti-IL-5-Therapie (Tag 8 in der 2,5-mg-Dosisgruppe; Tag 8,14 und 29 in der 10-mg-Dosisgruppe) kein Effekt nachweisen: gegenüber Plazebo keine signifikante Reduktion des $\mathrm{FEV}_{1}$-Abfalls $\geq 3 \mathrm{~h}$ nach Allergenprovokation [62]. Damit bestätigen sich prinzipiell die in einer tierexperimentellen Studie erhobenen Ergebnisse, in der mit Ovalbumin sensibilisierten Mäusen sich mit einem Antikörper gegen IL-5 die chemotaktische Wirkung auf Eosinophile und die allergische Früh-, nicht jedoch die Spätreaktion reduzieren ließ [63]. Die fehlende Signifikanz in der humanen Studie von Leckie et al. (1999) begründeten die Autoren u.a. mit den unterschiedlichen Ausgangswerten der drei Gruppen [62]. Da diese Studie primär zur Evaluation von Sicherheits- und Tolerabilitätsaspekten konzipiert wurde, erfolgte nur eine Einmalgabe und dies nur an einer kleinen Patientengruppe, weswegen bezüglich einer umfassenderen Beurteilung des klinischen Effektes weitere, insbesondere Phase-III-Untersuchungen (u.a. mit
Mehrfachgaben, größeres Patientenkollektiv), abgewartet werden müssen. Diese werden derzeit durchgeführt (SB240563, SCH55700).

\section{IL-5-Transkriptionshemmung}

Eine andere interessante Alternative zur IL-5-Hemmung kommt aus der Molekularbiologie. Das IL-5-Gen ist auf Chromosom 5 lokalisiert und besteht aus 4 Exons und 3 Introns. Die mRNA besteht aus 402 Nucleotidbasen, wobei die ersten 22 Aminosäuren die Signalsequenzen enthalten. Die 5'-Promotorregion des IL-5-Gens enthält auch durch Kortikosteroide regulierbare Elemente, weswegen Steroide die IL-5Expression unterdrücken können. Zur Transkriptionshemmung wurden antisense Oligonucleotide entwickelt, d.h. kurze, komplementär zur spezifischen mRNA aufgebaute Nukleodidsequenzen (GenBank Accession Number: X04688), die das „Ablesen“ der mRNA blockieren und somit die IL-5Bildung unterbinden. In-vitro-Untersuchungen an aus peripherem humanen Blut isolierten mit Phorbolmyristateacetate (PMA) aktivierten mononukleären Zellen zeigten, dass Oligonucleotide in der Lage sind, die IL-5-Transkription vollständig zu hemmen [64]. Wie schwierig es ist, In-vitro-Ergebnisse auf die In-vivo-Situation zu übertragen, zeigen die Untersuchungen von Molet et al. (1999) [65]. Es wurden in dieser Studie CD4+-Lymphozyten aus zervikalen Lymphknoten Ovalbuminsensibilisierter Ratten isoliert, ex vivo mit IL-4- oder IL-5antisense Oligonucleotiden inkubiert und diese Zellen naiven Ratten intraperitoneal implantiert. Nur in den IL-4-, nicht jedoch den IL-5-antisense behandelten Tieren, konnte eine Reduktion der allergischen Spätreaktion, der Eosinophilie und der IL-4-/IL-5-Expression festgestellt werden [65]. Die zukünftige klinische Realisierbarkeit eines solchen Therapieprinzips erscheint nach derzeitigem Kenntnisstand in absehbarer Zeit allerdings fraglich.

\section{IL-4-Inhibition}

Da IL-4 ein Mediator der beim Asthma unerwünschten Th2Antwort ist (u.a. steigert IL-4 die Expression von Adhäsionsmolekülen), wurde versucht, auch mit IL-4-Antikörpern einen antiinflammatorischen Effekt zu erzielen. Die Ergebnisse sind aber erst präliminär. Der vor der Ovalbumin-Sensibilisierung Mäusen applizierte IL-4-Antikörper mit dem Kürzel 11B11 unterband die IgE-Synthese [66]. Der IL-4 Antikörper BAY 169996 bindet an die $\alpha$-Kette des IL-4-Rezeptors. An Primaten konnte damit eine Reduktion der bronchialen Hyperreaktivität (Methacholin) demonstriert werden. Obwohl nach der Gabe von $0,5 \mathrm{mg} / \mathrm{kg}$ subkutan $(2 \times / \mathrm{d}$, Applikation parallel $\mathrm{zu}$ inhalativ gegebenen Ascaris-Extrakten) die bronchiale Hyperreaktivität $\left(\Delta \log \mathrm{PC}_{100}\right.$ ) um bis zu $64 \%$ (Tag 24 ) sank, wurde das Signifikanzniveau $(p=0,057)$ nicht erreicht [67]. Auch IL13 hemmt IL-4, da dieses Zytokin an die Alphakette des IL-4Rezeptors bindet und diesen blockiert [68]. Auch hier konnte mit IL-4-antisense Oligonucleotiden bei Mäusen eine Reduktion der allergischen Spätreaktion, der Eosinophilie und der IL-4- und IL-5-Expression erzielt werden [65].

Auch durch die Gabe eines löslichen IL-4-Rezeptors (soluble IL-4 receptor $=$ sIL-4R) lässt sich freies IL4 binden und damit biologisch inaktivieren. In vivo sensibilisierte Maus-Lymphozyten wurden in vitro re-stimuliert und a) mit löslichem Maus-sIL-4R, bzw. mit b) einem dimerischen sIL-4R Ig 
Fusionsprotein inkubiert. Mit beiden Rezeptoren ließen sich die IgE-Produktion um ca. 70\% und die des IgG1 um ca. 35\% reduzieren [69]. Sowohl die intraperitoneale als auch die inhalative Gabe von sIL-4R reduzierte in Ovalbumin-sensiblierten Mäusen die allergische Sofortreaktion mit Senkung der IgE-Spiegel und Normalisierung der Atemwegswiderstände [70]. 62 Patienten erhielten in einer plazebokontrollierten, doppelt-verblindeten und randomisierten Phase-II-Studie (Studiendauer: 12 Wochen) folgende sIL-4R-Konzentrationen per inhalationem $(1 \times /$ Woche $)$ verabreicht: $0,75 \mathrm{mg}(\mathrm{n}=15)$; $1,5 \mathrm{mg} \quad(\mathrm{n}=16) ; 3,0 \mathrm{mg} \quad(\mathrm{n}=15) ;$ Plazebo $(\mathrm{n}=16)$. In der Plazebogruppe verschlechterte sich die $\mathrm{FEV}_{1} \mathrm{um}-13,2 \%$, in der Verumgruppe $(3,0 \mathrm{mg})$ nur um $-2,3 \%(p=0,053)$. Die Ergebnisse der morgendlichen $\mathrm{FEV}_{1}$-Messungen waren eindeutiger: Plazebo $-0,541$ vs. $-0,091$ ( $p<0,02)$. Die Halbwertszeit betrug ca. 1 Woche. An Nebenwirkungen traten auf (Vergleich sIL-4R vs. Plazebo): Kopfschmerzen 13\% vs. $1 \%$; Erbrechen 13\% vs. 0\%; Infektionen des oberen Respirationstraktes $11 \%$ vs. $6 \%$; Schmerzsymptome $11 \%$ vs. $1 \%$ [71]. Größere Studien mit sIL-4R wurden zur breiteren Bestätigung der klinischen Wirksamkeit von den Autoren angekündigt.

\section{Adhäsionsmoleküle}

Die Bedeutung der Adhäsionsmoleküle beim akuten Asthma bronchiale ist mit dem Nachweis ihrer Expression durch verschiedene Entzündungszellen, z.B. VLA-1 (very late antigen) in T-Helfer-Lymphozyten, lange bekannt [72]. Die beim Asthma bronchiale typische Entzündungsreaktion erfordert die Rekrutierung der verschiedensten o.g. Entzündungszellen. Diese Migration aus dem Kapillarbett zum Ort des Entzündungsgeschehens - beim Asthma bronchiale vorzugsweise Eosinophile, Granulozyten, Mastzellen und Lymphozyten wird durch die sog. Adhäsionsmoleküle und deren entsprechende Rezeptoren gewährleistet und findet zielgerichtet von den Kapillaren zum Bronchialepithel, dem Ort des Entzündungsgeschens beim Asthma, statt (Abb.4). Die Adhäsion und Migration intravasaler Entzündungszellen zum Entzündungsort ist beim Asthma bronchiale sehr komplex und soll daher nur auf mögliche therapeutische Ansatzmöglichkeiten im kurzen Überblick dargestellt werden.

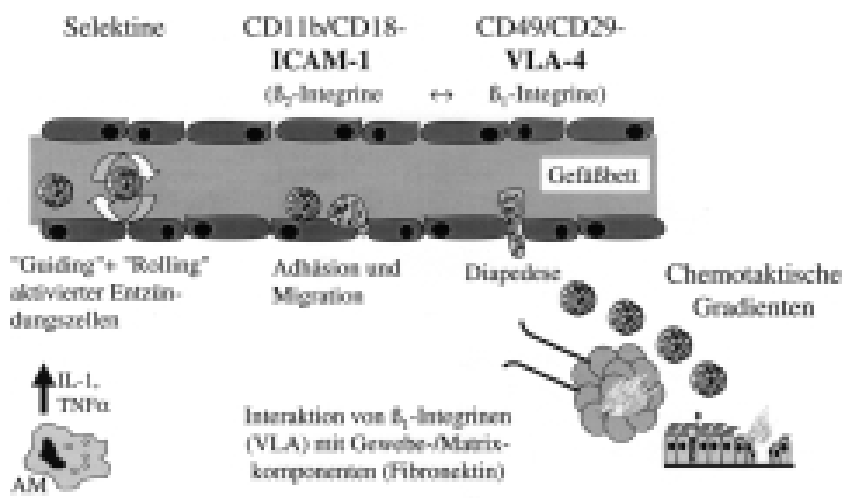

Abb. 4 Schematische Übersicht über die Rekrutierung von Entzündungszellen aus dem Gefäßsystem zum Entzündungsgeschehen (guiding und rolling $\rightarrow$ Adhäsion an Endothelzellen der Gefäßwand $\rightarrow$ Migration durch die Gefäßwand [Diapedese] $\rightarrow$ Transmigration durch das Lungeninterstitium) und der dabei beteiligten Adhäsionsmoleküle.
Folgende Adhäsionsmoleküle und deren Liganden sind dabei von pathophysiologischer Bedeutung: a) die vorwiegend in den Endothelzellen der entzündungsnahen Gefäße nachgewiesenen Selectine (E-, P- und L-Selectin), und b) die Integrine (VLA-4; LFA-1 [CD11a/CD18]; MAC-1 [CD11b/CD18]; P150,95; ACT-1 $\left[\alpha_{4} \beta_{7}\right]$ ), die primär auf der Oberfläche von Lymphozyten, Neutrophilen, Basophilen, Mastzellen und Monozyten nachgewiesen werden. Diese Adhäsionsmoleküle reagieren mit für sie spezifischen Liganden wie z.B. SialyLewis $\mathrm{x}\left(\mathrm{sLe}^{\mathrm{x}}\right)$ oder Mucine für die Selektine, den interzellulären Adhäsionsmolekülen (ICAMs) oder Fibronektin für die Integrine, und VCAM-1 für ACT-1. Die Produktion sowohl der Selectine und Integrine, als auch deren Liganden werden durch Zytokine selektiv gesteuert und sind spezifisch für bestimmte Zelltypen. So wird z.B. VCAM-1 nur nach IL-4Stimulation vermehrt bereitgestellt und bindet Lymphozyten, Monozyten, Basophile und Eosinophile, nicht aber Neutrophile.

\section{Therapeutische Adhäsionsmolekülehemmung}

Ziel der Blockade von Adhäsionsmolekülen (und/oder deren Liganden) ist letztendlich die Minimierung der Entzündungszellzahl in den Atemwegen und den beteiligten Gewebestrukturen. Hierzu wurden noch keine klinischen Studien publiziert. Lediglich in tierexperimentellen, meist an Ovalbuminsensibiliserten Nagern durchgeführten Untersuchungen ließen sich mit Antkörpern gegen ICAM-1, VLA-1, VLA-4 oder MAC-1 die allergische Früh- und Spätreaktion zusammen mit der entsprechenden zellulären Reaktion (Reduktion von Basophilen, Eosinophilen und Lymphozyten) hemmen [73 - 77].

\section{Resümee der medikamentösen Anti-Zytokintherapie}

Ohne Zweifel handelt es sich bei den hochselektiven pharmakologischen Interventionen in das Mediatorsystem um wissenschaftlich wie klinisch ausgesprochen interessante Therapieansätze (Abb.5). Obwohl der Eingriff in das Zytokinnetzwerk im Sinne eines antiinflammatorischen Wirkansatzes logisch erscheint, ist die praktische Umsetzung schwierig, da es kein zentral regulierendes „Schlüsselinterleukin“ gibt. Es stellt sich somit die kritische Frage, ob ein pharmakologischer Eingriff an nur einer einzigen Stelle des in sich verzahnten und durch seine ausgesprochene Komplexität charakterisierten Zytokinnetzwerkes überhaupt einen klinischen Effekt haben kann. Zwangsläufig werden in einem solchen Ansatz viele Wechselwirkungen unberücksichtigt bleiben oder es werden neue Wechselwirkungen entstehen, die möglicherweise den gewünschten Effekt neutralisieren, intensivieren, oder die vielleicht zu einem ganz neuen Verständnis der pathophysiologischen Vorgänge führen können. Gleiches gilt prinzipiell auch für die Adhäsionsmolekülhemmung. Außerdem müssen potentielle Nebenwirkungen eines solchen antiinflammatorischen Therapieansatzes berücksichtigt werden, denn in den in dieser Übersicht zitierten tierexperimentellen Arbeiten - Studien am Menschen waren teilweise noch nicht verfügbar - berücksichtigen diesen Aspekt naturgemäß kaum oder gar nicht.

Wichtig erscheinen im Rahmen dieser Überlegungen auch der Zeitpunkt und Ort des pharmakologischen Eingriffs in das immunologische Entzündungsgeschehen. Während nämlich die in der Asthma-Therapie überaus wirkungsvollen und 


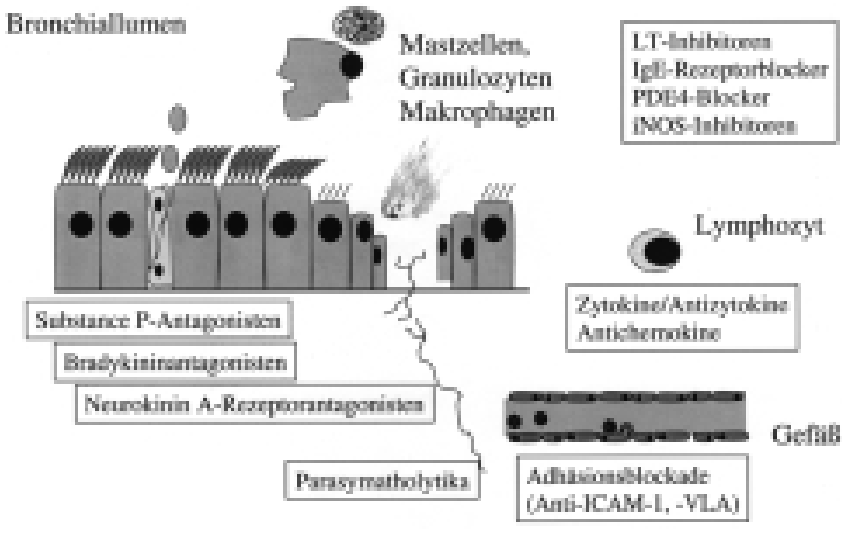

Abb. 5 Übersicht über pharmakologische Möglichkeiten zur direkten und indirekten Hemmung der Entzündungsreaktion beim Asthma bronchiale. $\mathrm{LT}=$ Leukotriene, $\mathrm{PDE}=$ Phosphodiesterasen, $\mathrm{iNOS}=$ induzierbare NO-Synthase.

unselektiv wirkenden Kortikosteroide schon sehr früh, d.h. auf der Ebene der Transkriptionsfaktoren wirken, greifen Antagonisten (z.B. anti-IgE-, anti-IL-5-Antikörper, Hemmung des Adhäsionsmechanismus oder Leukotrienrezeptorantagonisten) sehr selektiv und/oder vergleichsweise spät in das Entzündungsgeschehen ein, was sich auf die klinische Effektivität auswirken dürfte. Derzeit ist bei vielen der hier vorgestellten therapeutischen Konzepte nicht abzusehen, welche Eingang in die Asthmatherapie finden werden. Vielfach sind die entsprechenden Ansätze nur tierexperimentell evaluiert worden. Die Übertragbarkeit dieser Ergebnisse auf den Menschen ist jedoch nur eingeschänkt möglich.

Ohne Zweifel wird die weitere Entwicklung neuer Therapeutika zur Behandlung des Asthma bronchiale interessant bleiben. Die Zukunft wird zeigen, welcher Ansatz sich in humanen (Phase III)-Studien und später im klinischen Alltag bewährt, welcher schließlich die Marktreife erlangen wird und welchen zusätzlichen Beitrag die jeweilige Substanz zur Verbesserung der Symptomatik gegenüber der derzeitigen ohnehin schon in der Praxis verfügbaren und überaus potenten Substanzen leisten kann.

\section{Literatur}

${ }^{1}$ Bateman ED, Britton M, Carrillo T, Almeida J, Wixon C. Salmeterol/fluticasone combination inhaler. A new, effective and well tolerated treatment for asthma. Clin Drug Invest 1998; 16: 193 201

${ }^{2}$ Chapman KR, Ringdal N, Backer V, Palmqvist M, Saarelainen S, Briggs M. Salmeterol and fluticasone propionated $(50 / 250 \mu \mathrm{g})$ administered via combination diskus inhaler: as effective as when given via separate diskus inhalers. Can Respir J 1999; 6: 45-51

${ }^{3}$ Fairfax AJ, Spelman R. 400 MCG HFA-Beclomethasone dipropionate extrafine aerosol $\left(\mathrm{QVAR}^{\mathrm{TM}}\right)$ demonstrates equivalent improvement in asthma control to 400 MCG CFC-Fluticasone propionate (Flixotide ${ }^{\mathrm{TM}}$ ). Am J Respir Crit Care Med 1999; 159: A630

${ }^{4}$ June D. Achieving the change: challenges and success in the formulation of CFC-free MDIs. Eur Respir Rev 1997; 7: 32 - 34

${ }^{5}$ Schultze-Werninghaus G. Langzeittherapie des Asthma bronchiale im Erwachsenenalter. Internist 1999; 40: 855-860
${ }^{6}$ Berkovitz RB, Roberson S, Zora J, Capano D, Chen R, Lutz C, Harris AG. Mometasone furoate nasal spray is rapidly effective in the treatment of seasonal allergic rhinitis in an outdoor (park), acute exposure setting. Allergy Asthma Proc 1999; 20: 167-172

${ }^{7}$ Kanniess F, Richter K, Magnussen H. Effect of inhaled ciclesonide on hypersensitivity to AMP, induced sputum and exhaled nitric oxide in subjects with bronchial asthma. Eur Respir J 14; 1999 : 289s

${ }^{8}$ Fraser CM, Venter JC. Beta-adrenergic receptors. Am Rev Respir Dis 1990; 141: S22-S30

${ }^{9}$ Pueringer RJ, Casale TB. Functional activity of lower-airway nerves. In: Busse WW, Holgate ST (Hrsg.). Asthma and Rhinitis. Cambridge, Massachusetts, USA: Blackwell Science, Inc., 1995: $635-651$

${ }^{10}$ Laitinen LA, Laitinen A. Neural System. In: Crystal RG, West JB (Hrsg.). The Lung, scientific foundations. New York: Raven Press, 1991: 759- 765

${ }^{11}$ Casale TB, Ecklund P. Characterization of muscarinic receptor subtypes on human peripheral lung. J Appl Physiol 1988; 65: $594-600$

${ }^{12}$ Lin RY, Pesola GR, Bakalchuk L, Morgan JP, Heyl GT, Greyberg CW, Cataquet D, Estfal RE. Superiority of ipratropium plus albuterol over albuterol alone in the emergency department management of adult asthma: a randomized clinical trial. Ann Emerg Med 1998; 31: 208-213

${ }^{13}$ Qureshi F, Pestian J, Davis P, Zaritsky A. Effect of nebulized ipratropium on the hospitalization rates of children with asthma. N Engl J Med 1998; 339: 1030-1035

${ }^{14}$ Bonnert RV, Brown RC, Chapman D, Cheshire DR, Dixon J, Ince F, Kinchin EC, Lyons AJ, Davis AM, Hallam C, Harpert ST, Unitt JF, Dougall IG, Jackson DM, McKechnie K, Young A, Simpson WT. Dual D2-receptor and beta2-adrenoceptor agonists for the treatment of airway diseases. 1. Discovery and biological evaluation of some 7-(2-aminoethyl)-4-hydroxybenzothiazol-2(3H)one analogues. J Med Chem 1998; 41: 4915-4917

15 Young A, Dougall IG, Blackham A, Jackson DM, Hallam C, Harper JW. AR-C68397AA: The first dual $\mathrm{D}_{2}$-receptor and $\beta_{2}$-adrenoceptor agonist. Am J Respir Crit Care Med 1999; 159: A522

${ }^{16}$ Young A, Jackson DM, Taylor C, Ince F, Hallam C, Harpert ST. The $\mathrm{D}_{2}$-Receptor agonist related activity of AR-C68397AA, a novel dual $D_{2}$-receptor \& $\beta_{2}$-adrenoceptor agonist. Am J Respir Crit Care Med 1999; 159: A811

${ }^{17}$ Barnes PJ, Belvisi MG, Mak JC, Haddad EB, O'Connor BJ. Tiotropium bromide (Ba $679 \mathrm{BR}$ ), a novel long-acting muscarinic antagonist for the treatment of obstructive airways disease. Life Sci 1995; 56: $853-859$

${ }^{18}$ Diamond J. Role of cyclic GMP in airway smooth muscle relaxation. Agents Actions 1993; 43: $13-26$

${ }^{19}$ Giembycz MA, Raeburn D. Current concepts on mechanisms of force generation and maintenance in airways smooth muscle. Pulm Pharmacol 1992; 5: 279-297

${ }^{20}$ Rabe KF, Dent G, Magnussen H. Pharmakodynamik des Theophyllins. In: Ukena D, Keller A, Nolte D (Hrsg.). Theophyllin Controller and Reliever bei Asthma und COPD. München-Deisenhofen: Dustri-Verlag Dr. Karl Feistle, 1999: 1 - 39

${ }^{21}$ Barnes PJ. Methylxanthines and phosphodiesterase inhibitors. In: Busse W, Holgate ST (Hrsg.). Asthma and rhinitis. Cambridge, Massachusetts: Blackwell Science, 1995: 1267-1277

${ }^{22}$ Gillissen A. Bewertung der Theophyllin-Therapie beim Asthma bronchiale. Münch Med Wschr 1997; 139: 79-82

${ }^{23}$ Nicholson CD, Challiss RAJ, Shahid M. Differential modulation of tissue function and therapeutic potential of selective inhibitors of cyclic nucleotide phosphodiesterase isoenzymes. Trends Pharmacol 1991; 12: 19-27

${ }^{24}$ Beasley SC, Cooper N, Gowers L, Gregory JP, Haughan AF, Hellewell PG, Macari D, Miotla J, Montana JG, Morgan T, Naylor 
R, Runcie KA, Tuladhar B, Warneck JB. Synthesis and evaluation of a novel series of phosphodiesterase IV inhibitors. A potential treatment for asthma. Bioorg Med Chem Lett 1998; 1998: $2629-2634$

${ }^{25}$ Spina D, Landells LJ, Page CP. The role of theophylline and phosphodiesterase 4 isoenzyme inhibitors as anti-inflammatory drugs. Clin Exp Allergy 1998; 28: 24-34

${ }^{26}$ Harbinson PL, MacLeod D, Hawksworth R, O’Toole S, Sullivan PJ, Heath P, Kilfeather S, Page CP, Costello J, Holgate ST, Lee TH. The effect of a novel orally active selective PDE4 isoenzyme inhibitor (CDP840) on allergen-induced responses in asthmatic subjects. Eur Respir J 1997; 10: 1008 - 1014

${ }^{27}$ Compton CH, Cedar E, Nieman RB, Amit O, Langley SJ, Sapene M. Ariflo $^{\mathrm{TM}}$ improves pulmonary function in patients with asthma: results of a study in patients taking inhaled corticosteroids. Am J Respir Crit Care Med 1999a; 159: A624

${ }^{28}$ Compton CH, Cedar E, Nieman RB, Amit O, Langley SJ, Sapene M. SB 207499 improves pulmonary function in patients with asthma receiving concomitant inhaled corticosteroids. Eur Respir J 1999b; 14: 288s

${ }^{29}$ Compton CH, Gubb J, Cedar E, Bakst A, Nieman RB, Amit O, Ayres J, Brambilla C. Ariflo ${ }^{\mathrm{TM}}$ (SB 207499) a second generation, oral PDE4 inhibitor, on quality of life in patients with COPD. Am J Respir Crit Care Med 1999; 159: A522

${ }^{30}$ Murdoch RD, Clark D, Kelley J, Cowley H, Zussman B, Benincosa L, Webber D. Ariflo ${ }^{\mathrm{TM}}$ (SB-207499) an orally active second generation selective PDE4 inhibitor, does not interact with a variety of commonly co-administered COPD medications. Am J Respir Crit Care Med 1999; 159: A525

${ }^{31}$ Montana J, Cooper N, Hunt H, Oxford J, Gristwood R, Lowe C, Kendall H, Buckley G, Maxey R, Warneck J, Gregory J, Gowers L, Galleway F, Naylor R, Tudhalar B, Broadley K, Danahay H. Activity of D4418, a novel phosphodiesterase 4 (PDE4) inhibitor, effects in cellular and animal models asthma and early clinical studies. Eur Respir J 1999; 14: 290s

${ }^{32}$ Aizawa $H$, Inoue $H$, Nakano $H$, Matsumoto $K$, Yoshida $M$, Fukuyama S, Koto $\mathrm{H}$, Hara $\mathrm{N}$. Effects of thromboxane A2 antagonist on airway hyperresponsiveness, exhaled nitric oxide, and induced sputum eosinophils in asthmatics. Prostaglandins Leukot Essent Fatty Acids 1998; 59: 185-190

${ }^{33}$ Baba K, Hattori T, Sakakibara A, Kobayashi T, Takagi K. The usefulness of pranlukast of seratrodast for step-down of inhaled corticosteroid therapy in adult chronic asthma. Am J Respir Crit Care Med 1999; 159: A626

${ }^{34}$ Ishida T, Saitoh T, Obara M, Murakami O, Hayashibara K, Watanabe $S$. The effect of thromboxane $A_{2}$ receptor antagonist, seratrodast in mild to moderate asthma. Am J Respir Crit Care Med 1999; 159: A626

35 Arakida Y, Suwa K, Ohga K, Yokota M, Miyata K, Yamada T. In vitro pharmacologic profile o YM158, a new dual antagonist for LTD $_{4}$ and TXA 2 receptors. J Pharmacol Exp Ther 1998; 287: 633 639

${ }^{36}$ Hussein Z, Samara E, Locke CS, Orchard MA, Ringham GL, Granneman GR. Characterization of the pharmacokinetics and pharmacodynamics of a new oral thromboxane A2-receptorantagonist AA-2414 in normal subjects: population analysis. Clin Pharmacol Ther 1994; 55: 441 - 450

${ }^{37}$ Hoshino M, Sim J, Shimizu K, Nakayama H, Koya A. Effect of AA2414 , a thromboxane A2 receptor antagonist, on airway inflammation in subjects with asthma. J Allergy Clin Immunol 1999; 103: $1054-1061$

38 Obase Y, Shimoda T, Matsuo N, Matsuse H, Asai S, Kohno S. Effects of cysteinyl-leukotriene receptor antagonist, thromboxane A2 receptor antagonist, and thromboxane A2 synthetase inhibitor on antigen-induced bronchoconstriction in patients with asthma. Chest 1999; 114: $1028-1032$
${ }^{39}$ Magnussen H, Boerger S, Templin K, Baunack AR. Effects of thromboxane-receptor antagonist, BAY u 3405, on prostaglandin D2- and exercise-induced bronchoconstriction. J Allergy Clin Immunol 1992; 89: 1119-1126

${ }^{40}$ Sanjar S. Glaxo Wellcome research pipeline in chronic obstructive pulmonary disease. Eur Respir Rev 2000; 10: 370-373

${ }^{41}$ Ishizaka K, Ishizaka T. Identification of gamma-E antibodies as a carrier of reagenic activity. J Immunol 1967; 99: 1187

42 Johannson SGO, Bennick H. Immunological studies of an atypical (mycloma) immunoglobulin. Immunology 1967; 13: 381 - 394

${ }^{43}$ Metzger H, Rivnay B, Henkart M, Kanner B, Kinet JP, PerezMontort R. Analysis of the structure and function of the receptor for immunoglobulin E. Mol Immunol 1984; 21: 1167-1173

${ }^{44}$ Semper AE, Hartley JA. Dendritic cells in the lung - what is their relevance to asthma? Clin Exp Allergy 1996; 26: 485-490

${ }^{45}$ Bozelka BE, McCants ML, Salvaggio JE, Lehrer SB. IgE isotype suppression in anti- $\varepsilon$ treated mice. Immunology 1982; 46: $527-$ 532

${ }^{46}$ Marone G, Spadaro G, Palumbo C, Condorelli G. The anti-IgE/ anti-FcERI $\alpha$ autoantibody network in allergic and autoimmune diseases. Clin Exp Allergol 29; 1999: 17-27

${ }^{47}$ Shields RL, Whether WR, Zioncheck K, O'Connell L, Fendly B, Presta LG, Thomas D, Saban R, Jardieu P. Inhibition of allergic reactions with antibodies to IgE. Int Arch Allergy Immunol 1995; 107: $308-312$

${ }^{48}$ Boulet LP, Chapman KR, Coté J, Kalra S, Bhagat R, Swystun VA, Laviolette M, Cleland LD, Deschesnes F, Su JQ, DeVault A, Fick Jr $\mathrm{RB}$, Cockroft W. Inhibitory effects of an anti-IgE antibody E25 on allergen-induced early asthmatic response. Am J Respir Crit Care Med 1997; 155: 1835-1840

${ }^{49}$ Casale TB, Bernstein IL, Busse WW, LaForce CF, Tinkelman DG, Stoltz RR, Dockhorn RJ, Reimann J, Su JQ Fick RB, Adelman DC. Use of an anti-IgE humanized monoclonal antibody in ragweedinduced allergic rhinitis. J Allergy Clin Immunol 1997; 100: $110-$ 121

${ }^{50}$ Fahy JV, Fleming E, Wong HH, Liu JT, Su JQ, Reimann J, Fick Jr RB, Boushey HA. The effect of an anti-IgE monoclonal antibody on the early- and late phase response to allergen inhalation in asthmatic subjects. Am J Respir Crit Care Med 1997; 155: 1828 1834

${ }^{51}$ Fox JA, Hotaling TE, Struble C, Ruppel J, Bates DJ, Schoenhoff MB. Tissue distribution and complex formation with IgE of an antiIgE antibody after intravenous administration in cynomolgus monkeys. J Pharmacol Exp Ther 1996; 279: 1000-1008

${ }^{52}$ Metzger H, Fick RB. Corticosteroid (CS) withdrawal in a study of recombinant humanized monoclonal antibody to IgE (rhuMAbE25). J Allergy Clin Immunol 1998; 101: S231

${ }^{53}$ Demoly P, Bousquet J. Anti-IgE therapy for asthma. Am J Respir Crit Care Med 1997; 155: 1825-1827

${ }^{54}$ Howarth PH, Bradding P, Quint D, Redington AE, Holgate ST. Cytokines and airway inflammation. In: Chignard M, Pretolani M, Renesto P, Vargaftig BB (Hrsg.). Cells and cytokines in lung inflammation. New York: New York Academy of Sciences, 1994: $69-82$

${ }^{55}$ Zangrilli JG, Peters SP. Cytokines in allergic airway disease. In: Busse W, Holgate ST (Hrsg.). Asthma and rhinitis. Cambridge: Blackwell Science Inc., 1999: 426-436

${ }^{56}$ Pauwels RA, Brusselle GG, Tournoy KG, Lambrecht BN. Cytokines and their receptors as therapeutic targets in asthma. Clin Exp Allergol 1998; 28: 1 -5

${ }^{57}$ Park CS, Choi YS, Ki SH, Moon SH, Jeong SW, Uh ST, Kim YH. Granulocyte macrophage colony-stimulating factor is the main cytokine enhancing survival of eosinophils in asthmatic airways. Eur Respir J 1998; 12: 872 - 878 
${ }^{58}$ Danzig M, Cuss F. Inhibition of interleukin-5 with aa monoclonal antibody attenuates allergic inflammation. Allergy 1997; 52: $787-794$

59 Ohnishi T, Kita H, Weiler D, Sur S, Sedgwick J, Calhoun WJ, Busse WW, Abrams JS, Gleich GJ. IL-5 is the predominant eosinophilactive cytokine in the antigen-induced pulmonary late-phase reaction. Am Rev Respir Dis 1993; 147: $901-907$

${ }^{60}$ Ohnishi T, Sur S, Collins DS, Fish JE, Gleich GJ, Peters SP. Eosinophil survival activity identified as interleukin-5 is associated with eosinophil recruitment and degranulation and lung injury twenty-four hours after segmental antigen lung challenge. J Allergy Clin Immunol 1993; 92: 607-615

${ }^{61}$ Kaminuma O, Mori A, Ogawa K, Kakata A, Kikkawa H, Naito K, Suko M, Okudaira H. Successful transfer of late phase eosinophil infiltration in the lung by infusion of helper T cells clones. Am J Respir Cell Mol Biol 1997; 16: 448 -454

${ }^{62}$ Leckie MJ, Brinke ten A, Lordan J, Kahn J, Diamant Z, Walls CM, Cowley H, Webber D, Hansel TT, Djukanovic R, Sterk PJ, Holgate ST, Barnes PJ. A humanized anti-IL-5 monoclonal antibody: initial single dose safety and activity in patients with asthma. Am J Respir Crit Care Med 1999; 159: A624

${ }^{63}$ Cieslewicz G, Tomkinson A, Adler A, Duez C, Schwarze J, Takeda K, Larson KA, Lee JJ, Irvin CG, Gelfand EW. The late, but not early, asthmatic response is dependent on IL-5 and correlates with eosinophil infiltration. J Clin Invest 1999; 104: $301-308$

${ }^{64}$ Weltman JK, Karim AS. Interleukin-5: a proeosinophil cytokine mediator of inflammation in asthma and a target for antisense therapy. Allergy Asthma Proc 1998; 19: 257-261

${ }^{65}$ Molet S, Ramos-Barbon D, Martin JG, Hamid Q. Adoptively transferred late allergic response is inhibited by IL-4, but not IL5, antisense oligonucleotide. J Allergy Clin Immunol 1999; 104: $205-214$

${ }^{66}$ Zhou CY, Crocker IC, Koenig G, Romero FA, Townley RG. Antiinterleukin-4 inhibits immunoglobulin E production in a murine model of atopic asthma. J Asthma 1997; 34: 195-201

${ }^{67}$ Harris P, Lindell D, Fitch N, Gundel R. The IL-4 receptor antagonist (BAY 16-9996) reverses airway hyperresponsiveness in a primate model of asthma. Am J Respir Crit Care Med 1999; 159: A230

${ }^{68}$ Hogan SP, Foster PS, Tan X, Ramsey AJ. Mucosal IL-12 gene delivery inhibits allergic airways disease and restores local antiviral immunity. Eur J Immunol 1998; 28: 413-423

${ }^{69}$ Renz H, Enssle K, Lauffer L, Kurrle R, Gelfand EW. Inhibition of allergen-induced IgE and IgG1 production by soluble IL-4 receptor. Int Arch Allergy Appl Immunol 1995; 106: 46-54

${ }^{70}$ Renz H, Bradley A, Enssle K, Loader J, Larsen GL, Gelfand EW. Prevention of the development of immediate hypersensitivity and airway hyperresponsiveness following in vivo treatment with soluble IL-4 receptor. Int Arch Allergy Appl Immunol 1996; 109: $167-176$

71 Borish LC, Nelson HS, Bensch G, Corren J, Busse W, Whitmore J, Agosti J. Phase I/II study of soluble interleukin-4 receptor (IL-4R) in adults with moderate asthma. Eur Respir J 1999; 14: 288s

72 Corrigan CJ, Kay AB. CD4 T lymphocyte activation in acute severe asthma. Int Arch Allergy Appl Immunol 1991; 94: 270-271

${ }^{73}$ Nagase T, Fukuchi Y, Matsuse T, Sudo E, Matsui H, Orimo H. Antagonism of ICAM-1 attenuates airway and tissue response to antigen in sensitized rats. Am J Respir Crit Care Med 1995; 151: $1244-1249$

${ }^{74}$ Rabb HA, Olivenstein R, Issekutz TB, Renzi PM, Martin JG. The role of leukocyte adhesion molecules VLA-4, LFA-1, and Mac- 1 in allergic airway responses in the rat. Am J Respir Crit Care Med 1994; 149: $1186-1191$

${ }^{75}$ Sagara H, Matsuda H, Wada N, Yagita H, Fukuda T, Okumura K, Makino S, Ra C. A monoclonal antibody against very late activation antigen-4 inhibits eosinophil accumulation and late asth- matic response in a guinea pig model of asthma. Int Arch Allergy Appl Immunol 1997; 112: 287-294

${ }^{76}$ Stamatiou PB, Hamid Q, Taha R, Yu W, Issekutz TB, Rokach J, Khanapure SP, Powell WS. 5-Oxo-6,6,11,14-eicosatetraeoic acid stimulates eosinophil infiltration into rat lungs in an integrindependent fashion. Am J Respir Crit Care Med 1999; 159: A33

${ }^{77}$ Tomkinson A, Cieslewicz G, Duez C, Lee JJ, Gelfand EW. Lung eosinophilia and relationship to airway hyperresponsiveness (AHR) in mice: effect of IL-5 and VLA-4 antibody. Am J Respir Crit Care Med 1999; 159: A228

${ }^{78}$ Kroegel C, Herzog V, Förster M, Braun R. Pathogenetische Grundlagen des Asthma bronchiale. In: Kroegel C (Hrsg.). Asthma bronchiale. Stuttgart: Thieme, 1998: 13-51

Prof. Dr. med. A. Gillissen

Medizinische Klinik und Poliklinik II

Rheinische Friedrich-Wilhelms-Universität Bonn

Sigmund-Freud-Str. 25

53105 Bonn

E-mail: adrian.gillissen@meb.uni-bonn.de 